\title{
How Well Does Undergraduate Education Prepare College Students for the Employment Outlook? A Secondary Data Analysis of Baccalaureate and Beyond Longitudinal Study (B\&B)
}

\author{
Liyun $\mathrm{Wu}^{1} \&$ Marilyn W. Lewis ${ }^{1}$ \\ ${ }^{1}$ School of Social Work, Norfolk State University, Norfolk, Virginia, USA \\ Correspondence: Liyun Wu, School of Social Work, Norfolk State University, 700 Park Avenue, Norfolk, 23504, \\ Virginia, USA. Tel: 1-757-823-9037. E-mail: 1wu@nsu.edu
}

Received: September 10, 2019

Accepted: October 25, 2019 Online Published: November 5, 2019

doi:10.5539/hes.v9n4p181

URL: https://doi.org/10.5539/hes.v9n4p181

\begin{abstract}
The trajectory of successfully completing an undergraduate educational program, attaining postgraduate employment, and beginning advanced degree programs was examined using the Baccalaureate and Beyond Longitudinal Study (B\&B: 2008/2012), a large U.S. nationally representative longitudinal sample survey of college graduates who completed the requirements for a baccalaureate degree. The third cohort of this longitudinal study was used to compare participants' status at the time of graduation and four years post-graduation. It was hypothesized that graduates whose post baccalaureate employment experiences related to their baccalaureate majors would be more likely to enroll in additional advanced degree studies, and that the post-baccalaureate field of study would be similar to the undergraduate major among those who pursued a graduate degree. Race, gender, disability, and immigration status were entered as control variables. Findings show that within two years, $42.1 \%$ of graduates had initiated postsecondary education. These data indicate that graduates were more likely to pursue degrees which were similar to their baccalaureate degree majors. If their bachelor degree majors were health professions, the likelihood that they pursued graduate-level health professional training and related sciences were highest $(p<.001)$. By attending and finishing college, baccalaureate degree recipients heavily invest in their career by using their financial and non-financial resources. College students with fewer resources are less likely to successfully graduate, attain post-graduate employment in their field, and pursue post-baccalaureate studies. Instituting a competency-based curriculum in baccalaureate programs may improve opportunities for students to gain successful employment experiences, increase labor market outcomes, thus narrowing the divide between students with and without financial and non-financial resources.
\end{abstract}

Keywords: graduate study, undergraduate study, employment, major, higher education

\section{Introduction}

\subsection{Competency-based Education}

At the undergraduate level, competency-based education refers to a standard that requires students to meet standardized criteria before they are promoted from one level to the next. These criteria are based on achievement of learning standards and are in contrast to social promotions. Competency-based educational standards provide educators with information that identify deficits in the learners' knowledge base. Requirements may be established by the academic institution, the profession's accrediting body, or the state or local accreditation committees. Basing educational standards on competencies indicates that the learner has met certain milestones that prepare him or her for post-graduate employment. Because success is based on achievement, competency-based educational programs require a successful graduate to master the material necessary for success in the profession. The standards that must be met in order to demonstrate attainment of knowledge are in line with the requirements of the student's chosen profession.

Global competencies such as reading, writing, math, and critical thinking are transferable to many professions. However, some professions, especially those that come under a credentialing body, require the undergraduate student to demonstrate successful acquisition of education-specific competencies. Employment is a proxy for having met competency standards as specific requirements for work, and is evidence of successful completion of 
competency-based education. For example, undergraduate students who major in biology must achieve global competencies but also become proficient in area-specific knowledge, including laboratorial skills. Graduates who successfully obtain employment in laboratories demonstrate that they have met criteria and have mastered competencies in a given field.

\subsection{Literature Review on Education and Employment}

Level of education is directly related to employment rates in the United States. According to the Bureau of Labor Statistics (BLS) in August 2017, people with some college education had the lowest unemployment rate (3.8\%), compared to their counterparts with a high school degree $(5.1 \%)$ or less than high school degree $(6.0 \%)$. Even though college educated individuals tend to be employed, they may be working in jobs that do not require a baccalaureate degree. Despite the low unemployment rate, Bloomberg (2017) found that college graduates were employed in non-college jobs at an elevated level and in 2016, 44\% were employed in jobs that did not require a college degree. Rajecki (2008) evaluated BLS data for the most significant single source of education or training of entry-level workers and found that the most important type of education or training for these jobs was a moderate amount of on-the-job training. Clearly, many of the bachelor-trained workers were overqualified for their positions. Rajecki evaluated levels of training for 24 occupations and found that jobs that were staffed by workers with baccalaureate degrees or higher were social and human service assistants (57.2\%), advertising sales agents $(54.8 \%)$, and sales representatives (49.6\%). For professions that involve helping, counseling, or health-related activities, Rajecki found the positions required at least baccalaureate and often post-graduate training and were filled by clinical psychologists, counseling psychologists, personal/home care aides, psychiatric aides, and social workers. Typically, education or training for these jobs is competency-based and requires students to meet criteria established by the profession's accrediting body. The mismatch of training with employed workers in lower level jobs may result in workers choosing to return to school.

Even though many graduates with baccalaureate degrees are employed in jobs where they are overqualified, Appleby (2018) states that in some professions, like psychology, weak support is given to students who are not preparing to go directly into graduate school. He attributes the low rate (13\%) of graduates who held baccalaureate degrees in psychology and who went on to earn an advanced degree in the field of psychology, to the lack of support from their faculty. This is of concern because graduates with bachelor degrees in psychology often find themselves in positions that are unsatisfying. The American Psychological Association (APA) 2013 guidelines for psychology majors state that graduates are often overqualified for entry level jobs and become dissatisfied with their positions. This prompts a proportion of these bachelor-trained workers to seek graduate-level education in their area or switch altogether and enter fields where global knowledge gained from their study of psychology contributes to their success (business, social work, health care, education). Switching fields is often the case because as Rajecki and Borden (2010) state, skills that one learns as an undergraduate psychology student actually help students develop traits that are useful in other professions, such as critical thinking and ability to understand how to work with numbers.

Trajectories of individuals who choose postgraduate paths differ in several ways. Appleby (2018) cites the 1961 Michigan Report of the State of Education's data regarding trajectory of three groups of students: those preparing to enter graduate school in their same discipline as their baccalaureate degree (psychology); those preparing for graduate school in another discipline; and those who plan to use their undergraduate education to enter the workforce. He proposes that some faculty consider the education for this last group to be "vocational training" because its goal is not to obtain an advanced training in psychology. Appleby argues that it is this group that receives less academic support from faculty which creates further disparities in labor market outcomes. This is problematic because while $47 \%$ of freshmen stated that they planned to enter a PhD program, a majority of students graduating with a psychology major chose to obtain employment and not begin a graduate program immediately after graduation (Appleby, 2018). Rajecki and Borden (2010) found that almost half (49\%) their sample of baccalaureate trained psychology majors who had opted for employment indicated that a degree was not needed for the job they were employed in during the first year post graduation. This was similar to what humanities and social science graduates reported (45\%). A group of these underemployed graduates may elect to go to graduate school, either in the field of their undergraduate studies or another field, or they may elect to change their trajectory and enter a different career path.

Factors in addition to being overqualified for the position will affect this decision. Recently graduated employees reported that their skills didn't consistently predict their salary (Rajecki and Borden, 2010) Thus, it is likely that entry level employees with a baccalaureate degree in psychology or humanities and social sciences would either switch careers where they could make more money and use their earned degree, or go back to college and become educated for more career options. Lunneborg (1985) reported that persons with a baccalaureate degree in 
psychology were satisfied with their earnings if they also had studied engineering, business administration, and medicine, while those who were least satisfied with their earnings had studied humanities, social science, or education.

Satisfaction with one's level of income is only one aspect of job satisfaction. Lunneborg found that psychology graduates were happier when their skills were utilized (mental health therapists, special education teacher, high school teacher) but that those jobs were not identified as providing economic satisfaction. Occupations with the highest level of job dissatisfaction were bookkeepers, owners of small businesses, executive secretaries, administrative assistants, and department supervisors. Overall, they reported that they wish they had received business training. This group may include people who elect to pursue postgraduate work. Zhang (2014) reports that the amount of debt has a significant effect on whether a graduate opts for graduate work in an MBA program which may indicate that further education may be in a discipline other than business.

Pursuing graduate education can mean resuming studies in the same profession or changing trajectories and enter a different field. Palmer and colleagues (Palmer, Tolson, Young, \& Campbell, 2015) studied science, technology, engineering and math (STEM) professions and reported that baccalaureate trained engineers typically did not work in their field. They reported that in the United States there is a perception of a shortage of STEM graduates but in reality there is a surfeit. They found that approximately $75 \%$ of individuals with a STEM baccalaureate degree worked in an occupation outside STEM. Palmer and colleagues term this phenomena a "leaky STEM pipeline." Carnevale, Smith, and Melton (2011) reported that there were three reasons for the leakage. First, STEM trained graduates have the ability to use their STEM education to work in higher paying jobs in other professions. Second, their interests and values are better served by other professions. Third, the core knowledge, skills, and abilities that are relevant in a STEM profession can be desired by prestigious non-STEM occupations. They found that this STEM pipeline leakage is lessened if an employee goes on to pursue a master's degree in a STEM related area. They reported that this trajectory reduced the leakage to only $43 \%$ among recent graduates who didn't work in STEM occupations.

Zhang (2013) used the Baccalaureate and Beyond 93/97 survey to determine the effect of college debt on deciding to enter graduate school. Among graduates of public and private colleges, almost $50 \%$ who attended graduate school enrolled within 12 months of having received a bachelor's degree. This may reflect the students' dissatisfaction with their entry-level positions as stated earlier. Interestingly, the least likely group to attend graduate school were business majors, which may reflect their ability to become employed in a satisfactory job with their baccalaureate degrees or the high cost of further training. Zhang found that college graduates' student debt did not affect choice in other master's programs. Zhang compared students who attended public college with those who attended private college and found that students who attended private colleges were more likely to have borrowed more money (58\%) and have a higher average amount of debt. Zhang argues that students who graduate with higher levels of debt may be more likely to seek more lucrative occupations after they graduate, which may not lend itself to the most job satisfaction. However, it is unclear whether Zhang's sample attended post-graduate education in the same field or a related field.

\section{Method}

\subsection{Sample and Procedures}

This research utilized the third cohort of Baccalaureate and Beyond Longitudinal Study (B\&B) from the United States National Center for Education Statistics (NCES). This national representative study of postsecondary students yielded extensive information on the bachelor's degree recipients' undergraduate experience, demographic characteristics, community service, workforce participation, income, and debt repayment. The current study utilized the data from the 2008 cohort who was re-interviewed in 2012. Bachelor degree recipients were surveyed at the time of graduation (in 2008), one year after graduation (in 2009), four years of graduation (in 2012), and ten years after graduation (in 2018). The initial sample size was approximately 19,000 members who all obtained their BA/BS. The longitudinal data allow analyses of students' progress and persistence as they enter the graduate-level education and the workforce.

\subsection{Measurements}

\subsubsection{Dependent Variable}

All four dependent variables (DVs) were dichotomous. $\mathrm{DV}_{1}$ represented whether the individual enrolled in a master or higher degree program in 2012 which was four years after graduation in $2008 . \mathrm{DV}_{1}$ was based on the original variable "highest post-baccalaureate enrollment by degree type as of 2012." $\mathrm{DV}_{1}$ was coded as $1=$ master's degree or higher, and included master's degree, post-master's certificate, doctoral degree-professional 
practice degree, doctoral degree-research, other doctoral degree, and $0=$ other degrees. The other three DVs, $\mathrm{DV}_{2}-\mathrm{DV}_{4}$, were indicators of the respondent's graduate-level field of study: $\mathrm{DV}_{2}=$ whether pursued a graduate degree in humanities $(1=$ yes $) ; \mathrm{DV}_{3}=$ whether pursued a graduate degree in social science $(1=$ yes $)$; and $\mathrm{DV}_{4}=$ whether pursued a graduate degree in health professions $(1=$ yes $)$.

The respondent's major or field of study for the 2007-08 bachelor's degree was the key variable of interest in this study. The detailed description can be found in the original variable "MAJORS4Y." Variables DV $_{2}-\mathrm{DV}_{4}$ were not directly available and constructed by the researcher. The original variable was MAJORS4Y, which measured the major or field of study of the respondent's highest post-baccalaureate enrollment as of 2012 and included 45 categories (U.S. Department of Education National Center for Education Statistics, 2014). Based on those definitions, the researcher categorized the fields of study for humanities, social science, and health professions, respectively. The researcher then was able to construct a dichotomous indicator for graduate-level humanities $\left(\mathrm{DV}_{2}\right)$ by combining the following majors into one category: area, ethnic, cultural, gender, and group studies, English language and literature, foreign languages and literatures and linguistics, visual and performing arts, history, philosophy and religious studies. Similarly, a dichotomous indicator for graduate-level social science $\left(\mathrm{DV}_{3}\right)$ was identified by combining fields of study such as anthropology, criminology, economics, geography, international relations, political science, psychology, sociology, and other. Lastly, a dichotomous indicator for graduate-level health professions $\left(\mathrm{DV}_{4}\right)$ was identified by using the categories of health professions and related sciences such as allied health, pre-medical and pre-medical and pre-dentistry programs, mental and social health services, public health, veterinary medicine, and nursing.

\subsubsection{Independent Variables}

The first independent variable (IV) indicated whether the respondent's primary job in 2012 was related to his or her bachelor degree major, at four years since graduation in 2008. The $\mathrm{IV}_{1}$ was coded as a three-level categorical variable with $0=$ not related, $1=$ closely related, and $2=$ somewhat related. Another three $I V s\left(I_{2}, I_{3}\right.$, and $\left.I_{4}\right)$ were indicators of undergraduate-level field of study: $\mathrm{IV}_{2}=$ whether the respondent's bachelor major was in humanities; $\mathrm{IV}_{3}=$ whether the bachelor major was in social science; and $\mathrm{IV}_{4}=$ whether the bachelor major was in health care professions.

Based on the information available, the researcher constructed three pairs of graduate-undergraduate majors: humanities; social science; and health care related majors. Based on this breakdown, three dichotomous indicators were created: an indicator for humanities in the bachelor degree major $(1=$ yes $)$; an indicator for social science in bachelor degree major $(1=y e s)$; and an indicator for health care professions in bachelor degree major $(1=$ yes $)$, respectively.

\subsubsection{Control Variables}

The study also included control variables for a variety of demographic characteristics that are known to be related to employment and educational pursuits. . Gender was coded as $1=$ male and $0=$ female. The racial and ethnic variable was indicated by a set of dummy variables: White $(1=$ yes $)$; Black or African American $(1=$ yes); Hispanic $(1=$ yes $)$; and all other race/ethnicities. An indicator showed whether the person had a disability in 2007-08 ( $1=$ yes). An indicator of immigration status as of 2007-08 was created with $1=$ US born citizens and foreign born parents, $0=$ other.

\subsection{Research Questions and Hypotheses}

Four hypotheses will be tested. $\mathrm{H}_{1}$ was related to post graduation employment and $\mathrm{H}_{2}-\mathrm{H}_{4}$ were related to post-baccalaureate field of study. Hypothesis $1\left(\mathrm{H}_{1}\right)$ : Graduates whose primary jobs related to their bachelor degree majors were more likely to pursue graduate level degrees four years after undergraduate graduation. Hypothesis $2\left(\mathrm{H}_{2}\right)$ : Graduates who majored in humanities as undergraduates were more likely to pursue graduate-level degree in humanities. Hypothesis $3\left(\mathrm{H}_{3}\right)$ : Graduates who majored in social sciences as undergraduates were more likely to pursue graduate-level degree in social sciences. Hypothesis $4\left(\mathrm{H}_{4}\right)$ : Graduates who majored in health professions as undergraduates were more likely to pursue graduate-level degree in health professions. Overall, the post-baccalaureate field of study will be very similar to the bachelor degree major among those who pursued graduate degrees.

\subsection{Data Analysis}

Descriptive statistics were reported for all variables. A series of bivariate cross tabulations were presented to report the association between various predictors and dependent variables. Multivariate logistic regression was employed to examine the association between independent variables and dependent variables. 


\section{Results}

As shown in Table 1, 8.2\% of the graduating seniors in 2007-2008 self-reported that they had a disability (8.1\% male vs. $8.3 \%$ female). The racial/ethnicity breakdown was: White (72.7\%); Black or African American (8.8\%); Hispanic or Latino (9.4\%); Asian (5.9\%); and other ethnic groups. The breakdown of months between initial enrollment in postsecondary education and 2007-2008 baccalaureate degree award date was: Within 48 months (42.1\%); within 49-60 months (22.4\%); 61-72 months (9.8\%); 73-120 months (12.8\%); and more than 120 months (12.9\%). Field of study for ten categories of undergraduate majors was: Business (23.3\%); social science (15.19\%); humanities (11.67\%); education (8.19\%); health care fields $(7.58 \%)$; bio, physical science, math, and agriculture (7.35\%); engineering and engineering technology (5.96\%); general studies (3.03\%); computer and informational sciences (2.86\%); and other applied fields of study (14.87\%).

Table 1. Descriptive Statistics of All Variables

\begin{tabular}{ll}
\hline Variables & Percentage (\%) \\
\hline Dependent Variables & 35.71 \\
1, Whether pursued master or higher degree (1=yes) & 4.71 \\
2, Whether pursued graduate-level humanities degree (1=yes) & 6.50 \\
3, Whether pursued graduate-level social science degree (1=yes) & 24.82 \\
4, Whether pursued graduate-level health professions degree (1=yes) & \\
Independent Variables & \\
1, Primary job related to bachelor degree major, 4 years since graduation & 40.10 \\
Closely related & 31.40 \\
Somewhat related & 21.74 \\
Not related & 6.76 \\
N/A & 11.67 \\
2, Whether pursued bachelor degree major in humanities & 15.19 \\
3, Whether pursued bachelor degree major in social science & 7.58 \\
4, Whether pursued bachelor degree major in health professions & \\
Controlling variables & \\
Gender $\quad$ Male & 42.55 \\
Female & 57.45 \\
Race/Ethnicity & 72.7 \\
White & 8.8 \\
Black/ African American & 9.4 \\
Other & 9.1 \\
Had disability (1=yes) & 8.2 \\
Immigration status: First generation immigrant (1=yes) & 12.08 \\
\hline
\end{tabular}

Table 2 reported the results from the logistic regression analysis of predicting whether pursued graduate-level studies $\left(\mathrm{DV}_{1}\right)$. The odds ratio $(\mathrm{OR})$ indicated that graduates who worked in jobs closely related to their undergraduate major would be more likely to pursue advanced degrees (master degree or higher ) $(\mathrm{OR}=2.096$, $\mathrm{p}<0.001$ ), and graduates who worked in jobs somewhat related to their undergraduate major would also have a higher likelihood of pursuing advanced degrees $(\mathrm{OR}=1.475, \mathrm{p}=0.002)$. These data were compared to their counterparts whose primary jobs were not related to their bachelor degree majors. 
Table 2. Logistic Regression: Predicting Whether Pursued Graduate-Level Studies (0/1)

\begin{tabular}{|c|c|c|c|}
\hline Variable List & Odds Ratio & 95\% Confidence Interval (CI) & p-value \\
\hline \multicolumn{4}{|l|}{ Independent Variable } \\
\hline \multicolumn{4}{|l|}{ Primary job related to bachelor degree } \\
\hline Closely related & 2.096 & $1.649-2.665$ & $<0.001$ \\
\hline Somewhat related & 1.475 & $1.156-1.881$ & 0.002 \\
\hline \multicolumn{4}{|l|}{ Not related (reference group) } \\
\hline \multicolumn{4}{|l|}{ Controlling Variables } \\
\hline Gender $($ male $=1)$ & 1.349 & $1.102-1.651$ & 0.004 \\
\hline \multicolumn{4}{|l|}{ Race/Ethnicity } \\
\hline White & 1.063 & $0.774-1.461$ & 0.703 \\
\hline African American & 1.354 & $0.856-2.412$ & 0.194 \\
\hline Hispanic & 0.776 & $0.495-1.216$ & 0.267 \\
\hline \multicolumn{4}{|l|}{ Other (reference group) } \\
\hline Disability (Disabled =1) & 0.864 & $0.595-1.254$ & 0.439 \\
\hline First generation immigrants (Yes=1) & 0.822 & $0.412-1.241$ & 0.511 \\
\hline
\end{tabular}

Table 3A-3C reported the results from the logistic regression analysis of predicting three different areas of studies: humanities $\left(\mathrm{DV}_{2}\right)$, social science $\left(\mathrm{DV}_{3}\right)$, and health professions $\left(\mathrm{DV}_{4}\right)$, respectively. Graduates in general were more likely to pursue graduate-level degrees which were similar to their bachelor degree majors rather than degrees that were not related. If their bachelor degree majors were humanities, the likelihood of pursuing graduate-level humanities was high $(\mathrm{OR}=9.083, \mathrm{p}<0.001)$. If their bachelor degree majors were social science, the likelihood of pursuing graduate-level social science was also high $(\mathrm{OR}=9.656, \mathrm{p}<0.001)$. If their bachelor degree majors were health care fields, their likelihood of pursuing graduate-level health professions were the highest $(\mathrm{OR}=14.716, \mathrm{p}<0.001)$. Graduates who majored in bachelor-level health professions had the highlest likelihood to continue pursuing graduate-level education in the similar field of study.

Table 3. Logistic Regressions: Predicting Three Different Areas of Studies

Panel A: Predicting Whether the Respondent Pursued a Graduate-Level Degree in Humanities (0/1)

\begin{tabular}{llll}
\hline Variable List & Odds Ratio & $95 \%$ CI & p-value \\
\hline $\begin{array}{l}\text { Independent Variable } \\
\text { Bachelor degree major in humanities }\end{array}$ & 9.083 & $6.280-13.137$ & $<\mathbf{0 . 0 0 1}$ \\
$\begin{array}{l}\text { Controlling Variables } \\
\quad \text { Gender (male=1) }\end{array}$ & 0.804 & $0.560-1.153$ & 0.234 \\
$\quad \begin{array}{lll}\text { Race/ Ethnicity } \\
\quad \text { White }\end{array}$ & 0.865 & $0.467-1.605$ & 0.645 \\
$\quad$ African American & 0.698 & $0.300-1.622$ & 0.401 \\
$\quad$ Hispanic & 0.547 & $0.227-1.315$ & 0.176 \\
$\quad \begin{array}{lll}\text { Other (reference group) } \\
\text { Disability (Disabled =1) }\end{array}$ & 1.363 & $0.788-2.358$ & 0.266 \\
$\quad$ First generation immigrants (Yes=1) & 0.927 & $0.539-1.594$ & 0.782 \\
\hline
\end{tabular}

Panel B: Predicting Whether the Respondent Pursued a Graduate-Level Degree in Social Sciences (0/1)

\begin{tabular}{llll}
\hline Variable List & Odds Ratio & $95 \%$ CI & p-value \\
\hline $\begin{array}{l}\text { Independent Variable } \\
\text { Bachelor degree major in social sciences }\end{array}$ & 9.656 & $6.897-13.520$ & $<\mathbf{0 . 0 0 1}$ \\
$\begin{array}{l}\text { Controlling Variables } \\
\quad \text { Gender (male=1) }\end{array}$ & 1.016 & $0.732-1.412$ & 0.922 \\
$\quad \begin{array}{l}\text { Race/Ethnicity } \\
\quad \text { White }\end{array}$ & 0.764 & $0.448-1.305$ & 0.323 \\
$\quad$ African American & 0.851 & $0.438-1.653$ & 0.633 \\
$\quad$ Hispanic & 1.083 & $0.559-2.101$ & 0.812 \\
$\quad \begin{array}{lll}\text { Other (reference group) } \\
\quad \text { Disability (Disabled =1) }\end{array}$ & & \\
$\quad$ First generation immigrants (Yes=1) & 0.925 & $0.495-1.726$ & 0.804 \\
& 0.652 & $0.377-1.125$ & 0.124 \\
\hline
\end{tabular}


Panel C: Predicting Whether the Respondent Pursued a Graduate-Level Degree in Health Professions (0/1)

\begin{tabular}{lllc}
\hline Variable List & Odds Ratio & $95 \%$ CI & p-value \\
\hline $\begin{array}{l}\text { Independent variable } \\
\quad \text { Bachelor degree major in health professions }\end{array}$ & 14.716 & $10.201-21.230$ & $<\mathbf{0 . 0 0 1}$ \\
$\begin{array}{l}\text { Controlling variables } \\
\quad \text { Gender (male=1) }\end{array}$ & 0.505 & $0.411-0.620$ & $<\mathbf{0 . 0 0 1}$ \\
$\quad \begin{array}{l}\text { Race/Ethnicity } \\
\quad \text { White }\end{array}$ & 0.577 & $0.432-0.770$ & $<\mathbf{0 . 0 0 1}$ \\
$\quad$ African American & 0.623 & $0.416-0.933$ & $\mathbf{0 . 0 2 2}$ \\
$\quad$ Hispanic & 0.555 & $0.367-0.841$ & $\mathbf{0 . 0 0 6}$ \\
$\quad$ Other (reference group) & & & \\
$\quad \begin{array}{l}\text { Disability (Disabled =1) } \\
\text { First generation immigrants (Yes=1) }\end{array}$ & 0.829 & $0.577-1.191$ & 0.308 \\
\hline
\end{tabular}

\section{Discussion}

By attending and finishing college, college graduates heavily invested in their career by using their financial and non-financial resources. This study found two major research findings. First, graduates whose employment matched their bachelor degree majors were more likely to pursue a graduate-level degree rather than a nonrelated degree. This supports the notion that students whose post-graduate employment was in the field they studied showed competence required by the educational program and were prepared for employment. Second, graduates showed strong commitment to becoming specialists in their profession by pursuing further education in the same field of study. These findings may indicate that the students were prepared and didn't need remedial work to move ahead.

Because competency-based education is a relatively new strategy to improve education, students in deprived environments with poor educational facilities and resources, including instructors, may not be expected to meet competencies. This may have a negative impact on their career trajectory because they will compete with students who received better preparation as an undergraduate. This study sheds light on potential social justice issues that arise during preparation for a career. Identifying and choosing a major while an undergraduate student is one of the first steps in a career path. Because the choice of an academic major shapes both the educational experience and career path, it eventually can lead to disparity in unemployment, income, graduate program access, and other career indicators. Curran and colleagues (2011) proposed a method to develop and introduce a competency-based educational model to improve academic training. They advised that one begin by conducting an in-depth literature review to identify competencies that are germane to post-graduate employment and to hold focus group sessions to explore students, faculty, and employers' needs. While education for education's sake is a lofty pursuit, most young adults engage in undergraduate studies to prepare for a career. While this is the first phase of their trajectory, whether they begin employment in their major field, change their field of interest, or pursue an advanced degree in their undergraduate major, their trajectory can best be supported by educators who prepare them with expectations they meet criteria informed by competencies developed by the professions.

The study findings should be interpreted with the following limitations in mind. First, although this is a longitudinal study utilizing data points in 2008 and 2012, research findings from the multivariate analyses should be interpreted as relational, not causal. The positive predictive comparison does not necessarily have to be causal because the regression model can be subject to omitted variable bias. Second, this study utilized the broader category of bachelor's degree majors by combining majors into humanities, social science, and health professions, respectively. In future research, we can refine each major to discover the likelihood that students progressed into similar majors which they took as undergraduates. Despite these methodological limitations, this study, using a large U.S. national representative dataset of college graduates, contributes to the literature by examining the association between undergraduate education and its preparation for graduate-level studies.

\section{Conclusion}

By attending and finishing college, college graduates become heavily invested in their careers through using their financial and non-financial resources. This study found two major research findings. First, graduates whose jobs matched their bachelor degree majors had higher likelihood of further pursuing more advanced schooling. Second, graduates of undergraduate programs showed strong commitment to become specialized. They are committed to become professionals by obtain graduate-level degrees in the same major as their bachelor degree. 


\section{Acknowledgments}

This study received no external funding.

\section{References}

Appleby, D. C. (2018). Preparing psychology majors to enter the workforce: Then, now with whom, and how. Teaching of Psychology, 45(1), 14-23. https://doi.org/10.1177/0098628317744944

Carnevale, A. P., Smith, N., \& Melton, M. (2011). STEM: Science Technology Engineering Mathematics Executive Summary. Washington, D. C.: Georgetown University Center on Education and the Workforce.

Curran, V., Hollett, A., Casimiro, 1.M., Mccarthy, P., Benfield, V., Hall, P., Lackie, K., Oandasan, I., Simmons, B., \& Wagner, S. (2011). Development and validation of the interprofessional collaborator assessment rubric (ICAR). Journal of Inter professional Care, 25, 339-344. https://doi.org/10.3109/13561820.2011.589542

Lunneborg, P. W. (1985). Job satisfactions in different occupational areas among psychology baccalaureates. Teaching of Psychology, 12(1), 21-22. https://doi.org/10.1207/s15328023top1201_6

Palmer, S., Tolson, M., Young, K., \& Campbell, M. (2015). The relationship between engineering bachelor qualifications and occupational status in Australia. Australian Journal of Engineering Education, 20(2), 103-112. https://doi.org/10.1080/22054952.2015.1092666

Rajecki, D. W. (2008). Job lists for entry-level psychology baccalaureates: Occupational recommendation that mismatch qualifications. Teaching of Psychology, 35(1), 33-37. https://doi.org/10.1177/009862830803500109

Rajecki, D. W., \& Anderson, S. L. (2004). Career pathway information in introductory psychology textbooks. Teaching of Psychology, 31(2), 116-118.

Rajecki, D. W., \& Borden, V. M. H. (2010). Liberal Arts skills, psychology baccalaureates, and first-year employment: notes on a meritocracy hypothesis. Teaching of Psychology, 37(3), 157-164. https://doi.org/10.1080/00986283.2010.488550

U.S. Department of Education National Center for Education Statistics. (2018). A first look at the employment experiences and lives of college graduates, 4 Years on (B\&B: 08/12). NCES 2014-141. Retrieved from https://nces.ed.gov/pubs2014/2014141.pdf

Zhang, L. (2013). Effects of college educational debt on graduate school attendance and early career and lifestyle choices. Education Economics, 21(2), 154-175. https://doi.org/10.1080/09645292.2010.545204

\section{Copyrights}

Copyright for this article is retained by the author(s), with first publication rights granted to the journal.

This is an open-access article distributed under the terms and conditions of the Creative Commons Attribution license (http://creativecommons.org/licenses/by/4.0/). 